\title{
Portuguese Adaptation and Input for the Validation of the Views on Inpatient Care (VOICE) Outcome Measure to Assess Service Users' Perceptions of Inpatient Psychiatric Care
}

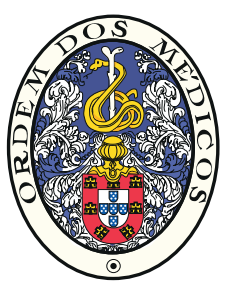

\section{Adaptação Portuguesa e Contribuição para a Validação da Medida Views on Inpatient Care (VOICE) para Avaliação da Satisfação com o Internamento Psiquiátrico}

\author{
João PALHA $\triangle^{1,2}$, Filipa PALHA ${ }^{2,3}$, Pedro DIAS ${ }^{3}$, Manuel GONÇALVES-PEREIRA ${ }^{4}$ \\ Acta Med Port 2017 Nov;30(11):790-795 - https://doi.org/10.20344/amp.8596
}

\section{ABSTRACT}

Introduction: Patient satisfaction is an important measure of health care quality. Patients' views have seldom been considered in the construction of measures addressing satisfaction with inpatient facilities in psychiatry. The Views on Inpatient Care - VOICE - is a first service-user generated outcome measure relying solely on their perceptions of acute care, representing a valuable indicator of service users' perceived quality of care. The present study aimed to contribute to the validation of the Portuguese version of VOICE.

Material and Methods: The questionnaire was translated into Portuguese and applied to a sample of eighty-five female inpatients of a psychiatric institution. Data analysis focused on assessing reliability and exploring the impact of demographic and clinical variables on participants' satisfaction.

Results: Internal consistency of the questionnaire was high $(\alpha=0.87)$. Participants' age and marital status were associated with differences in scores, with older patients and patients who were married or involved in a close relationship presenting higher satisfaction levels.

Discussion: The questionnaire demonstrated good internal consistency and acceptability, as well as construct validity. Further studies should expand the analysis of the psychometric properties of this measure e.g., test-retest reliability.

Conclusion: The Portuguese version of VOICE is a promising tool to assess service users' perceptions of inpatient psychiatric care in Portugal.

Keywords: Inpatients; Mental Health Services; Mentally III Persons; Patient Satisfaction; Portugal; Psychometrics; Surveys and Questionnaires

\section{RESUMO}

Introdução: A satisfação com os serviços de saúde é uma medida importante da qualidade dos cuidados formais prestados. Os doentes raramente têm sido envolvidos na construção de instrumentos para avaliar a satisfação com estruturas de internamento psiquiátrico. A medida Views on Inpatient Care (VOICE) recorre, pela primeira vez, às perceções dos próprios doentes sobre um internamento em cuidados agudos, apresentando-se como um indicador valioso da qualidade dos cuidados tal como percebida pelos utentes. $\mathrm{O}$ presente estudo visou contribuir para a validação da versão portuguesa desta medida.

Material e Métodos: O questionário foi traduzido e adaptado para português, e aplicado a uma amostra de 85 mulheres admitidas num serviço de internamento psiquiátrico. A análise focou-se na consistência interna da medida e no impacto das variáveis demográficas e clínicas nos níveis de satisfação.

Resultados: A consistência interna foi elevada $(\alpha=0,87)$. Encontrámos associações entre a idade e o estado civil e as pontuações obtidas: doentes mais velhos e doentes casados, ou vivendo maritalmente, apresentaram níveis mais elevados de satisfação.

Discussão: O questionário apresentou boa consistência interna e aceitabilidade entre os participantes, bem como validade de constructo. As propriedades psicométricas da escala deverão ser exploradas em vertentes adicionais, como a fiabilidade teste-reteste.

Conclusão: A versão portuguesa da medida VOICE é um instrumento promissor para avaliar a perspectiva dos doentes sobre o internamento psiquiátrico em Portugal.

Palavras-chave: Doentes Internados; Inquéritos e Questionários; Pessoas Mentalmente Doentes; Portugal; Psicometria; Satisfação do Doente; Serviços de Saúde Mental

\section{INTRODUCTION}

In the past two decades, the participation of patients with mental illness (also referred to in the literature as consumers or service-users) in decisions regarding mental health policies became uncontentious in many countries..$^{1-4}$

The World Health Organisation recently published the

'Mental health action plan 2013-2020, ${ }^{5}$ which states one of the proposed actions for member States is "to provide comprehensive, integrated and responsive mental health and social care services in community-based settings". The document emphasises that "more active involvement

1. Serviços Locais de Saúde Mental. Centro Hospitalar Póvoa de Varzim - Vila do Conde. Póvoa de Varzim. Portugal.

2. ENCONTRAR+SE: Associação para a Promoção da Saúde Mental. Porto. Portugal.

3. Centro de Estudos em Desenvolvimento Humano. Faculdade de Educação e Psicologia. Universidade Católica Portuguesa. Porto. Portugal.

4. CEDOC - Centro de Estudos de Doenças Crónicas. NOVA Medical School/Faculdade de Ciências Médicas. Universidade Nova de Lisboa. Lisboa. Portugal.

$\triangle$ Autor correspondente: João Palha. joaopalha@gmail.com

Recebido: 28 de dezembro de 2016 - Aceite: 20 de junho de 2017 | Copyright @ Ordem dos Médicos 2017 
and support of service users in the reorganization, delivery and evaluation and monitoring of services is required so that care and treatment become more responsive to their needs" (p. 14). ${ }^{5}$

There is an increasing recognition of the important role of service-users in planning, developing, implementing and assessing service provision and service development. This relies on the belief that service users obviously must inform the understanding of their own needs for care, as associated with personal experience of mental health problems, of the best ways of addressing them, and of which criteria should be considered when evaluating existing responses. ${ }^{6,7}$

Amongst the multiple aspects that need to be considered within mental health policies, assessing serviceusers' satisfaction with care is imperative to guarantee the provision of effective and efficient mental health services.

This has been done regarding outpatient services evaluation, through the development of tools such as the Verona Service Satisfaction Scale. ${ }^{8}$

Considering the nature and evolution of many mental health problems, inpatient care is a necessary part of the recovery process for some mental health service users, and therefore assessing psychiatric inpatient satisfaction has gained attention in recent years.

By reviewing self-reported instruments to assess psychiatric inpatient satisfaction, Boyer and collaborators ${ }^{1}$ identified fifteen instruments, all developed in Europe and the United States of America, varying greatly in terms of structure, content, generation process and level of documentation of psychometric properties. The authors highlighted there are no unique approaches to satisfaction measurement. The review also clarified that none of the instruments had been developed by service users. However, in some cases, users' views were considered in deriving a part of the satisfaction items' content. This raises the issue that most satisfaction measures have been developed by clinicians or academics. In the context of psychiatric care this may partially reflect the reluctance that still prevails in acknowledging that people with mental health problems may be reliable informers, and capable of being involved in research and policies. ${ }^{9-11}$

The Views on Inpatient Care (VOICE) ${ }^{9}$ is an instrument that tries to overcome such constraints. It was developed using an innovative methodology that involved service users throughout the research project as both participants and researchers, and relies solely on their perceptions of acute care. VOICE was the first service-user generated outcome measure, reflecting patients' experiences and views on acute settings, and as such should be considered a valuable indicator of service users' perceived quality of care. $^{9}$

Despite this growing emphasis on the importance of service users' involvement in mental health policies and research, ${ }^{10,12}$ many countries still have a long way to go before it is possible for patients to have such a role in influencing the mental health agenda. In Portugal, even though such need has been addressed within the National
Mental Health Plan (2007-2016) $)^{13}$ services are in many ways lagging behind what would be desirable in terms of considering patients' views on the provision of mental health care. This hampers the empowerment process that could contribute to the active participation and involvement of people with mental health problems, and probably conveys a negative impact in their recovery process.

The evaluation of satisfaction with services in inpatient units is by no means a routine approach in our country. Although there was a Portuguese research experience with the Maudsley Inpatient Satisfaction scale (MISS), ${ }^{14}$ the original English version of this questionnaire ${ }^{15}$ was not directly originated from users' contributions, thus sharing the aforementioned frailties of most satisfaction tools.

The present study was promoted by a Portuguese NGO (ENCONTRAR+SE) working for the promotion of mental health, and advocating for the provision of state-of-the-art community based services, through greater involvement of service users. We aim to contribute to the validation of the Portuguese version of VOICE, as an outcome measure that represents users' perspectives on the issues that need to be assessed in an inpatient unit.

\section{MATERIAL AND METHODS}

Prior to data collection, an agreement was made between the ENCONTRAR+SE NGO and King's College London to license the use of VOICE for this non-commercial clinical research.

\section{Setting and participants}

The present study was conducted in a psychiatric institution providing acute and long-term inpatient treatment for women, run by Sisters Hospitallers and with formal connections with the public health system.

Between January and May 2014 all inpatients admitted to the acute inpatient unit were invited to participate in the study, after completing 7 days of hospitalization. The mean length of hospitalization in this acute inpatient ward was 12.9 days in 2014.

\section{Assessment tools}

Views on inpatient care (VOICE) is a 19-item, selfreported measure of service users' perceptions of acute inpatient care. Service users developed it following a participatory methodology. VOICE addresses issues considered important for service users: admission; care and treatment; medication; staff; therapy and activities; environment, and ethnic and religious diversity. To complete VOICE, a six-point Likert scale ranging from 'strongly disagree' (1) to 'strongly agree' (6) is used. Optional freetext sections were originally included to obtain additional qualitative data, but these were not used in the present study. VOICE provides a final score that ranges from 19 to 114 , with higher scores indicating a more negative perception.

It is suitable for use in research settings. Psychometric properties of the original English version are robust, with 
high internal consistency $(\alpha=0.92)$ and high test-retest reliability $(\mathrm{n}=40)(\rho=0.88, \mathrm{Cl} 0.81-0.95){ }^{9}$

The full involvement of service users throughout the development of the measure ensured good face and content validity, as well as acceptability by the intended target group. Moreover, results of the original study indicated high criterion validity using a satisfaction with residential services' evaluation, and the ability of VOICE to discriminate between different groups (e.g., worse perceptions of care within those who had experienced a compulsory admission). ${ }^{9}$

For the present study, a questionnaire was developed to obtain the socio-demographic and clinical characterization of the sample, including the following aspects: age, marital status, employment, household, five-point Graffar's index to assess socio-economic status (SES) based on professional level, education, family income, housing conditions, and neighbourhood quality, ${ }^{16}$ self-reported diagnosis, years of psychiatric treatment, number of psychiatric visits and hospitalizations in the previous year, length of current hospitalization at time of completion of VOICE, type of hospital admission (voluntary / involuntary), type of therapy received during the admission (medication, psychotherapy, occupational therapy), and whether or not the user was given permission to be visited during hospitalization.

\section{Translation and adaptation of VOICE}

The translation of VOICE followed the standard procedures, which included: 1) two bilingual translators independently translated the items from the original English version to Portuguese; 2) once the initial translations were completed, the translators discussed small inconsistencies, and a composite translation was produced; 3) this final translation was back-translated to English by an independent translator, whose mother tongue is English and who had no knowledge of VOICE; 4) the original and the backtranslation were compared, and translators agreed on the final version.

Throughout the translation and back-translation process several contacts were established with one of the authors of VOICE (Evans J) with whom issues of wording and meaning of two items ( 3 and 16 ) were discussed. Regarding item 3, "Ward rounds are useful for me', clarification was provided that it means the meetings between the patient and the consultant psychiatrist (usually once a week) to decide on treatment/length of stay, amongst other issues. In the Portuguese version it became 'During hospitalization, appointments with the psychiatrist in charge are useful to me'. As far as item 16 is concerned 'I feel staff respond well when the panic alarm goes off', it refers to when there is an emergency with a patient (e.g. violence, selfharm) and someone hits the red button on the wall: a loud alarm then goes off which alerts staff. This is a question about safety and assesses whether patients think that staff respond appropriately, although this kind of alarm is not generalized in Portuguese wards. Therefore, in order to faithfully translate this idea into the Portuguese version, wording became "I think that the unit's staff responds well in emergency situations".

A pre-test of the instrument was conducted with five service-users who were asked about the perceived meaning of the questions, and whether there was any word or expression that they could not understand, or found unacceptable or offensive. VOICE was considered to be easy to understand and to complete, and thus suitable as a self-report assessment to be used by most service users whilst in an inpatient psychiatric facility.

\section{Data collection procedures and ethical aspects}

The study was approved by the administration and the ethical committee of the psychiatric institution.

Between January and May 2014, all inpatients admitted to the unit were invited to participate in the study, after completing seven days of hospitalization. All participants provided a written informed consent, after being given the opportunity to clarify any questions regarding the study.

\section{Data analysis}

The reliability of VOICE was assessed using Cronbach's alpha. ${ }^{17}$

Exploratory analyses were carried out in order to assess the impact of demographic variables on the level of patients' satisfaction, using independent-samples t-tests and Pearson correlations whenever data was normally distributed.

The significance level of $\alpha=5 \%$ was considered. All data were entered and analysed using the IBM Statistical Package for the Social Science for Windows 22.0 (IBM, Inc.).

\section{RESULTS}

\section{Sample characteristics}

A total of 85 women participated in the study. SES was in the middle-class range $(M=3.14 ; S D=0.64)$, and average household was of 2.9 persons (SD = 1.36). Table 1 presents demographic and clinical characteristics of patients.

Regarding aspects of the period of hospitalisation, twenty-one patients $(25.3 \%)$ were treated during their admission by the same psychiatrist who was responsible for their outpatient care. During the current hospitalisation most of them did not receive injectable drugs, including depot medication ( $n=73 ; 88 \% ; n=76 ; 91.6 \%$, respectively), did not attend psychotherapy sessions ( $n=65 ; 78.3 \%$ ), and were not allowed to receive visits ( $n=55 ; 67.1 \%$ ). On the contrary, most attended occupational therapy activities ( $\mathrm{n}=$ $61 ; 73.5 \%)$.

\section{Acceptability (ecological validity) and reliability}

Eighty-five participants took part in testing the psychometric properties of the VOICE. Seventy-eight had full data for all items on the VOICE scale, and five participants had over $80 \%$ response to VOICE items. Following the procedure reported by the authors of the instrument, ${ }^{9}$ for participants responding to at least $80 \%$ of the items, a pro-rated score was calculated; less than $80 \%$ 
Table 1 - Demographic and clinical characteristics of patients $(\mathrm{n}=85)$

\begin{tabular}{|cc}
\hline Age & (years) \\
\hline Minimum - Maximum & $18-77$ \\
Mean (SD) & $45.19(11.16)$ \\
\hline Marital status & (n / \%) \\
\hline Single / Divorced / Widow & $38(45.0)$ \\
Married / close relationship & $45(53.0)$ \\
Missing & $2(2.0)$ \\
\hline Professional status & (n / \%) \\
\hline Employed & $22(26.5)$ \\
Student & $2(2.4)$ \\
Retired & $20(24.1)$ \\
Unemployed & $20(24.1)$ \\
Sick leave & $14(16.9)$ \\
Other & $5(6.0)$ \\
\hline Diagnosis & (n / \%) \\
\hline Depression & $43(51.8 \%)$ \\
Bipolar disorder & $13(15.7)$ \\
Psychosis & $10(12.0)$ \\
Personality disorder & $10(12.0)$ \\
Addictive disorder & $4(4.8)$ \\
Other diagnoses & $3(3.6)$ \\
\hline Admission & (n / \%) \\
\hline Voluntary & $73(88.0)$ \\
\hline (12 months prior to hospitalization) & (n / \%) \\
\hline Outpatient consultation & $65(78.3)$ \\
\hline & $32(38.6)$ \\
\hline
\end{tabular}

response was considered as a missing total VOICE score.

Internal consistency of the Portuguese version of VOICE was high $(\alpha=0.87)$. All but one item presented high item-total correlations (ranging from 0.22 to $0.71 ; \mathrm{M}=0.54$; $\mathrm{SD}=0.15$ ). The exception was item 6 ("the staff gives me medication instead of talking to me"), which presented an item-total correlation of 0.18 .

\section{Impact of socio-demographic and clinical variables on satisfaction}

Participants' age was associated with differences in VOICE scores, with patients older than 45 years-old $(\mathrm{n}=$ 33) presenting significantly higher satisfaction ( $M=29.12$; $\mathrm{SD}=7.28)$ than patients aged between 18 and $44(\mathrm{n}=50$; $\mathrm{M}=34.74 ; \mathrm{SD}=10.83), t(81)=2.16, p=0.01$. We found no association between SES level and VOICE scores.

Patients who were married or involved in a close relationship $(n=45)$ presented significantly lower scores in VOICE, i.e. higher levels of satisfaction $(M=29.76$; SD $=8.61$ ), when compared to single, separated/divorced or widowed participants $(\mathrm{n}=38)(\mathrm{M}=35.76$; $\mathrm{SD}=10.48), t$ $(81)=-2.87, p=0.005$.

No significant differences were found regarding other socio-demographic variables (employment, household, socio-economic status); clinical variables (diagnosis, years of psychiatric treatment, number of psychiatric appointments and hospitalizations in the previous year); aspects of the experience of hospitalization (i.e. length of current hospitalization, type of hospital admission (voluntary/involuntary), type of psychosocial care received during hospitalizations (psychotherapy, occupational therapy), medication, and permission or not to be visited during hospitalization.

\section{DISCUSSION}

The present study aimed to translate, adapt and test the Portuguese version of Views on Inpatient Care - VOICE, an instrument developed by service users to assess their perceptions of acute psychiatric inpatient care. It is the first contribution to the validation of the Portuguese version of VOICE.

Regarding the instrument's validity, the pre-test conducted with a small group of service-users suggested the Portuguese version of VOICE revealed face and content validity, and acceptability in the main sample confirmed this impression.

On the other hand, group differences supported to some extent the construct validity of VOICE. Older patients, and those married or involved in a close relationship presented higher levels of satisfaction with inpatient care.

Older patients have been found to present greater levels of satisfaction with care in studies conducted in different settings, regardless of gender and diagnosis. ${ }^{18-20}$ Regarding marital status, similar results were found in a previous study with a larger sample. ${ }^{21}$

Despite these findings, the literature on patients' satisfaction with psychiatric hospitalization does not propose any explanation for such differences, simply reinforcing the complexities involved in patients' perception of satisfaction.

In fact, what needs to be recognised is the number of determinants influencing patients' levels of satisfaction, which include some aspects that can be controlled by staff and institutional characteristics (e.g. patient activities), and other issues lying outside the control of managers or clinicians (e.g. visits from family members and friends). ${ }^{20,22}$ The psychiatric facility where the study was conducted has a considerable number of long-term hospitalized patients, most of them aged above 60. Even though the ward where the present study took place is an independent one, these acute patients make contact with long-term residents in occupational activities or in the common areas (e.g. garden, coffee-shop). Considering that the mean age of the 277 long-term patients in this institution at the time of this study was 60 years, one can hypothesise that for older patients the possibility of relating with people of their age may be satisfying, while the same may not apply to younger people.

Furthermore, this study also demonstrated that during the time of hospitalization most patients were involved in occupational activities, but only a small number received psychotherapy sessions. Given the typical short-term 
length of admissions and distribution of diagnoses, this may have been an adequate response to individuals' clinical needs and not exactly a lack of concern from the team regarding person-centred approaches. Generally speaking, perhaps the improvement of in-patient mental healthcare standards in order to better address younger people (e.g. personalized care, daily one-to-one contacts, a recoveryoriented approach) still has a long way to go in facilities with such short-term admissions.

Regarding reliability, internal consistency as assessed by Cronbach's alpha was high.

Considering the average length of stay during the same year (12.9 days), test-retest reliability was not deemed possible to assess in the present study, right from the design stage, as we should preview a test-retest interval of at least one week.

Future studies should document further the psychometric properties of the Portuguese version of VOICE, including test-retest analysis.

Other limitations of our study should be acknowledged. We selected a non-randomised sample, which was biased towards middle age, and middle class. Furthermore, the small sample size and the fact that our study was carried out in one institution only (and one that is committed to the care of women) did not allow studying the impact on service users' satisfaction of gender, clinical variables, type of setting (private versus public), admission (first admission versus previous admissions), and legal status (voluntary versus compulsory). This should be considered in future studies.

\section{Implications of the findings}

The study of service users' satisfaction with mental health care is of utmost importance considering its potential impact on recovery, and this area of research is raising interest throughout the world. ${ }^{23}$ Patients' satisfaction with care, on one hand, and their participation in policy development, on the other, can predict future behaviours, such as adherence to treatment and willingness in seeking help for further needs, ${ }^{24,25}$ and greatly contribute to their empowerment and the quality of care. ${ }^{25}$ Such contribution can only occur if professionals and policy makers do accept service users' views, as 'partners in the management of their own health', ${ }^{20}$ engaging respectfully with people with mental illness within this new working alliance paradigm. ${ }^{26}$ Measures such as VOICE, based in participatory methods in order to capture users' perceptions more accurately, are a step forward regarding more conventional 'satisfaction' assessments. $^{9}$
Furthermore, it is evident that this is a complex area of research considering the number of possible influencing factors, both at an individual level, and regarding the characteristics of the facilities where care is provided. In fact, service users' level of satisfaction with inpatient care will always depend in part on users' demographics, life situations, levels of illness, amongst other personal and clinical variables, as well as on the practices that guide the management of services.

The recent socio-economic crisis has imposed several constraints in the health sector. Given that persons with mental health problems are among those with the least resources, this may have had an even greater impact on them. In Portugal, a country undergoing a reform in psychiatric care, ${ }^{13,27,28}$ this seems the right moment to account for issues regarding service users' satisfaction, so that we can move towards a higher quality of psychiatric care, including that of inpatient services.

\section{CONCLUSION}

We have translated and adapted the Portuguese version of VOICE, documenting internal consistency and construct validity. Validation of measures such as VOICE is a continuous process, and further research should test other psychometric properties (e.g. test-retest reliability, criterion validity), other populations, and cross-cultural issues related to content validity. Overall, VOICE is a promising tool to assess service users' perceptions of inpatient psychiatric care in Portugal.

\section{PROTECTION OF HUMANS AND ANIMALS}

The authors declare that the study was approved by the administration and the Ethics Committee of the psychiatric institution and was carried out in accordance to the Helsinki Declaration of the World Medical Association.

\section{DATA CONFIDENTIALITY}

The authors declare having followed the protocols in use at their working center regarding patients' data publication. Informed consent was duly obtained from the patient.

\section{CONFLICTS OF INTEREST}

All authors report no conflict of interest.

\section{FUNDING SOURCES}

This research received no specific grant from any funding agency in the public, commercial, or not-for-profit sectors.

\section{REFERENCES}

1. Boyer L, Baumstarck-Barrau K, Cano N, Zendjidjian X, Belzeaux R, Limousin S, et al. Assessment of psychiatric inpatient satisfaction: a systematic review of self-reported instruments. Eur Psychiatry. 2009;24:540-9.

2. Kleintjes S, Lund C, Swartz L, Flisher A. Mental health care user participation in mental health policy development and implementation in
South Africa. Int Rev Psychiatry. 2010;22:568-77.

3. Rose D. Service user produced knowledge. J Ment Health. 2009;17:44751.

4. Storm M, Davidson L. Inpatients and providers' experiences with user involvement in inpatient care. Psychiatr Q. 2010;81;111-25.

5. World Health Organisation. Mental health action plan 2013-2020. 
[Accessed 2016 Dec 23]. Retrieved from http://apps.who.int/iris/ bitstream/10665/89966/1/9789241506021_eng.pdf?ua=1.

6. Doughty $\mathrm{C}$, Tse S. Can consumer-led mental health services be equally effective? An integrative review of CLMH services in high-income countries. Community Ment Health J. 2011;47:252-66.

7. Rose D, Evans J, Sweeney A, Wykes T. A model for developing outcome measures from the perspectives of mental health service users. Int Rev Psychiatry. 2011;23:41-6.

8. Ruggeri M, Lasalvia A, Dall'Agnola R, van Wijngaarden B, Knudsen HC, Leese $\mathrm{M}$, et al. Development, internal consistency and reliability of the Verona Service Satisfaction Scale - European Version. Epsilon Study 7. European Psychiatric Services: Intputs Linked to Outcome Domains and Needs. Br J Psychiatry Suppl. 2000;39:s41-8.

9. Evans J, Rose D, Flach C, Csipke E, Glossop H, Wykes T. VOICE: developing a new measure of service users' perceptions of inpatient care, using a participatory methodology. J Ment Health. 2012;21:57-71.

10. Hopkins JE, Loeb SJ, Fick DM. Beyond satisfaction, what service users expect of inpatient mental health care: a literature review. J Psychiatr Ment Health Nurs. 2009;16:927-37.

11. Zendjidjian $X Y$, Baumstarck $K$, Auquier P, Loundou A, Lançon $C$, Boyer L. Satisfaction of hospitalizes psychiatric patients: why should clinicians care? Patient Prefer Adherence. 2014;8:575-83.

12. Rose D, Fleischman P, Wykes T. What are mental health service users' priorities for research in the UK?. J Ment Health. 2008;17:520-30.

13. Comissão Nacional para a Reestruturação dos Serviços de Saúde Mental. (2007). Reestruturação e Desenvolvimento dos Serviços de Saúde Mental em Portugal. Plano de Acção 2007 - 2016. Lisboa: Comissão Nacional para a Reestruturação dos Serviços de Saúde Mental. [Accessed 2016 Dec 23]. Retrieved from http:// www. portaldasaude.pt/NR/rdonlyres/CC4ABF07-1E93-4181-9E9E3B54D4C6C6A6/0/RELATÓRIOFINAL_ABRIL2007.pdf.

14. Nava AS, Sarmento CM, Gonçalves-Pereira M. Assessment of patient satisfaction in a Portuguese inpatient psychiatric unit. Proceedings of the VII Congress of the International Federation of Psychiatric Epidemiology (poster presentation), Sept 2000. Santiago de Compostela: IFPE; 2000.

15. Wykes T, Carroll S. Patient satisfaction with intensive care psychiatric services: Can it be assessed? J Ment Health. 1993:2:339-47.

16. Graffar M. Une méthode de classification sociale - échantillons de population. Courrier. 1956;6:445-59.

17. Cronbach LJ. Coefficient alpha and the internal structure of tests. Psychometrika. 1951;16:297-334.

18. Kressin NR, Skinner K, Sullivan L, Miller DR, Frayne S, Kazis L, et al. Patient satisfaction with Department of Veterans Affairs health care: do women differ from men? Mil Med. 1999;164:283-8.

19. World Health Organization. The World Health Report 2008. Primary health care: Now more than ever. Geneva: WHO; 2008.

20. Young GJ, Metereko M, Desai KR. Patient satisfaction with hospital care: effects of demographic and institutional characteristics. Med Care. 2000;38:325-34.

21. Hall JA, Dornan MC. Patient sociodemographic characteristics as predictors of satisfaction with medical care:a meta-analysis. Soc Sci Med. 1990;30:811-8

22. Sharac J, McCrone P, Sabes-Figuera R, Csipke E, Wood A, Wykes T. Nurse and patient activities and interaction on psychiatric inpatients wards: a literature review. Int J Nurs Stud. 2010;47:909-17.

23. Krupchanka D, Khalifeh H, Abdulmalik J, Ardila-Gómez S, Armiya'u A, Banjac V, et al. Satisfaction with psychiatric in-patient care as rated by patients at discharge from hospitals in 11 countries. Soc Psychiatry Psychiatr Epidemiol. 2017;1-15.

24. Crane-Ross D, Lutz WJ, Roth D. Consumer and case manage perspectives of service empowerment: Relationship to mental health recovery. J Behav Health Serv Res. 2006;33:142-55.

25. World Health Organization. The World Health Report 2001. Mental health: new understanding, new hope. Geneva: WHO; 2001.

26. McDaid S. An equality of condition framework for user involvement in mental health policy and planning: Evidence from participatory action research. Disabil Soc. 2009;24:461-74.

27. Caldas de Almeida JM. Portuguese National Mental Health Plan (20072016). Executive Summary. Ment Health Fam Med. 2009;6:233-44.

28. Palha A, Marques-Teixeira J. The emergence of psychiatry in Portugal: From its roots to now. Int Rev Psychiatry. 2012;24:334-40. 